\title{
High-speed aboveground transport - a new impetus for sustainable economic development
}

\author{
Evgeny Grigoriev ${ }^{1, *}$ and Anatoly Arkhipov ${ }^{1}$ \\ ${ }^{1}$ Siberian State University of Water Transport, 33, Shchetinkina, Novosibirsk, Russia
}

\begin{abstract}
Transport is a system-forming branch of the national economy, ensuring the territorial integrity and unity of the economic space. The development of economic processes, increasing competition and the increasing impact of economic ties, include the issues of improving the transport system among the priorities. The article analyzes the problems of modern transport systems, identifies the shortcomings of traditional modes of transport and the main directions of their development. The directions of innovative development of the transport system of Russia are analyzed. The review of innovative developments of high-speed transport, which allows to increase the integration potential of the regions and the mobility of the population, to reduce social tensions in remote regions from the central part of the country, to ensure the economic security of the country. Conclusions are drawn about the current state of implementation of such systems and prospects for application in Russia. The requirements for the new generation transport system are defined.
\end{abstract}

\section{Introduction}

It is widely known that Russia is majestic not only by the area of its territory, but also by the grandiose riches hidden in the bowels of its native land. It is home to only $2 \%$ of the world's population, which accounts for almost $40 \%$ of the world's natural resources. There are more than 20 thousand mineral deposits in the vast expanses of our country. Today, the value of Russia's mineral resources is estimated at $\$ 350$ trillion. or $\$ 2.5$ million for each citizen of the country. Russia has the largest number of neighboring countries-it borders on land with fourteen states with accessible land transport crossings, and its shores are washed by twelve seas belonging to the basins of three oceans.

Russia is characterized by a paradoxical discrepancy between its unique geographical, territorial resources, natural resources and its niche in the world economic system, which is determined, in particular, by inefficient transport systems. The country's transport security is heterogeneous and does not meet modern economic needs. The functioning and development of the national economy requires new, breakthrough solutions in the transport industry.

\footnotetext{
* Corresponding author: e.a.grigorev@mail.ru
} 


\section{Materials and Methods}

The research conducted by the authors of the article is based on dialectical methods of cognition and system-structural analysis, which allow us to evaluate the dialectic of economic and technological, general and private, regional and sectoral. This paper uses general scientific methods of theoretical and empirical cognition: analogy, analysis and synthesis, generalization and detailing, systematic approach, monographic description, transition from the abstract to the concrete.

\section{Results}

Studies have shown that the current development of the transport system of Russia and its regions does not fully meet the challenges, problems and requirements that the market of goods and services presents. At the same time, not only the domestic transport system is bogged down in problems - it is not ideal in other countries either. Modernization of traditional transport, as a rule, slightly, only by a fraction of a percent, improves its technical and economic characteristics, while huge funds are invested in the implementation of this goal. The introduction of new high-speed aboveground modes of transport will contribute to the enrichment of the transport system and increase its efficiency, they will act as a powerful catalyst for the socio-economic development of the country. The order of promotion and implementation of such innovations will depend on their potential effectiveness, the degree of elaboration at the current time, as well as on the competence and determination of government agencies and businesses.

\section{Analysis of the problems of modern transport systems and determination of their impact on the socio-economic state of the country}

The development of the transport system at the present stage does not sufficiently meet the tasks and requirements of the market of goods and services [1]. Depreciation of production assets of the transport system reaches almost $70 \%$ and continues to increase; in many regions, the lack of funds for the restoration of fixed assets leads to the actual destruction of the existing transport network; the cost of its maintenance and repair, as a rule, does not exceed $60 \%$ of the regulatory value.

The cost intensity of transportation is growing, which leads to an increase in the cost of transportation, and, consequently, to an increase in transport tariffs. With the exception of intercity bus and interregional air transportation, passenger transportation in domestic traffic is unprofitable, and the profitability of cargo transportation is minimal. The main reason for this is outdated technologies, low labor productivity, high costs for repairing rolling stock and transport infrastructure, and rising prices for consumed material and energy resources. The main burden on the maintenance of the transport system falls on the state, without significant participation of the private sector.

The economic development of the regions is hindered by a poorly developed road network, and the existing characteristics do not fully meet social and economic needs, as well as the growth of the level of motorization. The discrepancy between traffic flows and the size and capacity of the transport network in many regions contributes to the formation of multi-kilometer traffic jams and transport collapse [2]. Moreover, in some of the busiest areas, traffic jams of 8-9 points remain throughout the working day. Also, the growing load on the road network leads to accelerated destruction of road surfaces. 
In the context of the country's regions, there is an uneven development of transport infrastructure. The most significant differences are between the European part of Russia and the regions of Siberia and the Far East. The insufficient level of transport security hinders the comprehensive development of new territories and the development of mineral deposits. The lack of a developed regional transport structure leads to a reduction in settlements, mass migration of the population to cities.

The discrepancy between the parameters of motor transport and Russian railways to international standards is a serious problem for the implementation of the transit potential of Russia and the creation of transport corridors passing through the Siberian regions. Currently, new transport and transport and logistics technologies are being introduced in our country very poorly. The functioning and development of the national economy requires new, breakthrough solutions in the transport industry.

It is fair to note that not only the domestic transport system is bogged down in problems - it is not ideal in other countries. Leading transport-producing countries note a deep crisis in the development of the transport system. The world transport system is morally obsolete, and some of its elements have long been outdated and technically, since only minor changes have been made to it, without affecting the basics of the system.

It is obvious that the development of transport technologies does not keep pace with the development of society - in the XXI century, we use too slow and unreliable for our rapid life means of transportation, invented in the XIX century. In the figure below, the authors present only some features of traditional modes of transport.

The analysis of numerous scientific works allowed to reveal a number of the main directions of development traditional modes of transport that are being implemented at the present stage (see Table).

Table 1. Main directions of development of traditional modes of transport.

\begin{tabular}{|c|c|}
\hline Mode of transport & Directions of development \\
\hline $\begin{array}{l}\text { Automotive } \\
\text { transport }\end{array}$ & $\begin{array}{l}\text { Development and large-scale installation of eco-friendly cars; } \\
\text { Use of new technologies in road transport construction; } \\
\text { automation of management processes; } \\
\text { manage passenger traffic; } \\
\text { Coordinated use of vehicles to reduce them on the roads. }\end{array}$ \\
\hline Air transport & $\begin{array}{l}\text { Development and production of multifunctional and more } \\
\text { powerful types of vessels capable of performing complex } \\
\text { maneuvers and safely emerging from emergency situations; } \\
\text { supplies, reducing air pollution; } \\
\text { Improving the fuel efficiency, the use of the latest modern } \\
\end{array}$ \\
\hline Railway transport & $\begin{array}{l}\text { Improving the structure of track facilities, communication } \\
\text { and information channels, management; } \\
\text { Modernization of communication routes, power supply } \\
\text { facilities, development of technical base of repair works; } \\
>\quad \text { Renewal of rolling stock fleets. }\end{array}$ \\
\hline Water transport & $\begin{array}{l}\text { Replenishment of the fleet with new modern vessels, mainly } \\
\text { Russian-made, in order to attract investment in the industry; } \\
\text { Ship renovation; modernization, repair of water bodies at ship } \\
\text { repair enterprises; } \\
\text { resource-saving technologies. }\end{array}$ \\
\hline
\end{tabular}

At the same time, it should be noted that the modernization of traditional transport, as a rule, slightly, only by a fraction of a percent, improves its technical and economic 
characteristics, and huge funds are invested in academic, research and design work for the implementation of this goal.

\begin{tabular}{|c|c|c|c|c|c|}
\hline \multicolumn{6}{|c|}{ Features of traditional modes of transport } \\
\hline$\sqrt{2}$ & & & & & \\
\hline low transport speeds & \multicolumn{2}{|c|}{$\begin{array}{c}\text { high costs for the } \\
\text { construction, } \\
\text { maintenance and } \\
\text { operation of the track }\end{array}$} & \multicolumn{2}{|c|}{$\begin{array}{l}\text { damage to the } \\
\text { environment }\end{array}$} & $\begin{array}{r}\text { damage to } \\
\text { sph }\end{array}$ \\
\hline $\begin{array}{l}\text { For example, the speed } \\
\text { of cargo transportation } \\
\text { on rails, taking into } \\
\text { account technological } \\
\text { downtime, currently } \\
\text { does not exceed } 12 \\
\mathrm{~km} / \mathrm{h} \text { on average, and } \\
\text { on rivers- } 6 \mathrm{~km} / \mathrm{h} \text {; the } \\
\text { speed of road transport } \\
\text { is slightly higher, but } \\
\text { the growth in the } \\
\text { number of cars (which, } \\
\text { according to the } \\
\text { analytical agency } \\
\text { Autostat over the past } \\
10 \text { years in the Russian } \\
\text { Federation amounted } \\
\text { to } 30 \% \text { ), increasingly } \\
\text { leads to a decrease in } \\
\text { this indicator. }\end{array}$ & \multicolumn{2}{|c|}{$\begin{array}{l}\text { Thus, only the } \\
\text { construction of one } \\
\text { kilometer of the } \\
\text { railway line will cost } \\
\text { an average of } \$ 3 \\
\text { million, the highway - } \\
\$ 4 \text { million, the metro } \\
\text { line - \$ } 70 \text { million. }\end{array}$} & \multicolumn{2}{|c|}{$\begin{array}{l}\text { Up to } 80 \% \text { of pollution } \\
\text { in large cities makes } \\
\text { road transport; } \\
\text { absorption of oxygen } \\
\text { by one airliner at } \\
\text { takeoff is equal to the } \\
\text { oxygen uptake of a city } \\
\text { with a population of } \\
\text { several dozen thousand } \\
\text { people; for the } \\
\text { construction of roads, } \\
\text { bridges, alienated the } \\
\text { vast territory. }\end{array}$} & $\begin{array}{l}\text { For example } \\
\text { from a numb } \\
\text { transportatic } \\
\text { covered by t } \\
\text { budget, whic } \\
\text { negatively a } \\
\text { social progr }\end{array}$ \\
\hline \multicolumn{2}{|c|}{ high level of danger } & \multicolumn{2}{|c|}{$\begin{array}{c}\text { limitations in the use } \\
\text { of }\end{array}$} & \multicolumn{2}{|c|}{$\begin{array}{l}\text { low ratio of the weight } \\
\text { of the transported } \\
\text { (useful) cargo to the } \\
\text { weight of the rolling } \\
\text { stock }\end{array}$} \\
\hline \multicolumn{2}{|c|}{$\begin{array}{l}\text { According to the } \\
\text { World Health } \\
\text { Organization, } 1.35 \\
\text { million people die each } \\
\text { year on the world's } \\
\text { roads alone. In the } \\
\text { ranking of causes of } \\
\text { death, it is the eighth } \\
\text { cause of death for } \\
\text { Earth residents of all } \\
\text { ages and the main } \\
\text { cause of death among } \\
\text { residents aged } 5 \text { to } 29 \\
\text { years. }\end{array}$} & \multicolumn{2}{|c|}{$\begin{array}{l}\text { Restrictions on the } \\
\text { movement of trucks } \\
\text { during the occurrence } \\
\text { of unfavorable climatic } \\
\text { conditions; seasonality } \\
\text { of river transport, its } \\
\text { dependence on the } \\
\text { geography of } \\
\text { navigable rivers; } \\
\text { dependence of air } \\
\text { transport on weather } \\
\text { conditions, as well as } \\
\text { the high cost of } \\
\text { transportation, which } \\
\text { makes it inaccessible } \\
\text { to the majority of the } \\
\text { population, etc. }\end{array}$} & \multicolumn{2}{|c|}{\begin{tabular}{|l|} 
For example, in a \\
passenger train, 25 \\
tons of iron \\
(compartment car, \\
locomotive, rails) carry \\
only 1 ton of payload.
\end{tabular}} \\
\hline
\end{tabular}

Fig. 1. Features of traditional modes of transport. 


\section{High-speed transport as a factor in the development of productive forces and improving Russia's Economic Security}

The development of the transport system correlates with the challenges of our time associated with the growing needs for high speeds, safety, reliability, comfort and environmental friendliness. Such a development today is impossible to imagine without a highly efficient high-speed communication, built into the system of multimodal transport. The transport system faces large-scale challenges in creating new modes of transport, communication routes, technologies for their construction, and systems for their economic management. At the same time, the first place is not competition between modes of transport, but their cooperation [3-6].

According to the principle of W. Ashby - the higher the diversity of the system, the more viable it is, since the diversity of elements and connections of the system potentially contains forms of adaptation to different options for the future. Violation of the principle of necessary diversity leads to the death of the system. The emergence of a new mode of transport contributes to increasing this diversity, and, consequently, to improving the reliability of transport systems. The introduction of new modes of transport enriches the transport system and increases its efficiency. Thus, new modes of transport act as a powerful catalyst for the socio-economic development of the country.

The creation of a new, efficient, high-speed communication will allow: to reduce the time of distraction from the production activities of the active part of the population; to increase its mobility, which will not only change the structure of the labor market, but also indirectly affect the increase in labor productivity, opening access to jobs for people from remote regions; to increase the investment attractiveness of regions and the volume of trade exchange; to ensure the economic security of the country [7-10].

In recent decades, work has intensified on the creation of high-speed transport systems that do not use the wheel as the basis of the technology, since it has exhausted the potential of its development at a speed of $350 \mathrm{~km} / \mathrm{h}$. Today, humanity has concepts described and revised in prototypes and full-size models, in which, due to the air gap established through various technical solutions, there is no contact between the module and the infrastructure. In comparison with traditional technologies, such technologies have significant advantages and potential, at least by reducing infrastructure wear, energy consumption and significantly increasing speed. The implementation of such projects is now possible thanks to the existing innovative construction methods.

Such technical solutions include magnetolevitation transport technology; vacuum train; ship / train on an air (dynamic and statistical) cushion.

In magnetolevitation transport technology ("Maglev"), the air gap between the "train" module and the infrastructure occurs due to electromagnetic forces of attraction or repulsion, and the movement occurs due to a linear motor, which in some solutions also performs the functions of transverse stabilization and levitation [11]. The speed that such a train can reach is comparable to the speed of an airplane and is over $600 \mathrm{~km} / \mathrm{h}$, which allows it to compete with an aircraft on short - and medium-haul routes. The first patents for this technology were obtained in the XIX century. Currently, the development of Maglev is actively underway in Germany, China, Japan and South Korea (Transrapid, JR Maglev, etc.). The mass implementation of such transport systems is still constrained by the high costs of construction and maintenance of the route (the cost of $1 \mathrm{~km}$ of its construction can reach $\$ 50$ million). Moreover, there is a problem of the danger of the electromagnetic field of this transport-the electric motor, which hypothetically can have a negative impact on the environment and human health; there may also be interference in the operation of electrical appliances.

The vacuum train project became widely known after the attention of American venture 
entrepreneur Elon Musk to it. Such a project ("Hyperloop") is a passenger / cargo streamlined capsule with a length of $25-30 \mathrm{~m}$, placed in a vacuum tube, which eliminates air resistance when reaching high speeds (from 400 to $1220 \mathrm{~km} / \mathrm{h}$ (depending on the landscape)) $[12,13]$. The interval of movement of such a capsule will be no more than 30 seconds in one direction. The capsule is driven by a linear electric motor, and energy is provided by solar panels. It should be noted that the idea of such a variant of relocation appeared quite a long time ago - back in 1864, the Englishman T. V. Remmell built a track for the movement of pneumatic trains in Crystal Palace, and later on the basis of such technology, it was planned to create a metro network in New York-a pilot section was built under Broadway. However, this technology was never integrated into the transport system as a result of the fear of destruction of the foundations of the houses under which the route was supposed to pass.

Currently, several competing teams are working on the project at once, which accelerates the natural selection of ideas and solutions. The main difficulties at this stage of Hyperloop implementation are: ensuring the safety of people in the pipe in case of emergency situations and the problem of interaction with other modes of transport. In addition, experts of the Institute of Problems of Natural Monopolies note a high level of capital costs for the construction of $1 \mathrm{~km}$ of the track, which, without taking into account the cost of land alienation, will amount to more than $\$ 55$ million. (on the example of the Hyperloop line between Moscow and St. Petersburg), the high cost of tickets for passengers - from 16,100 to 48,900 rubles; high payback periods of the project.

A hovercraft (statistical or dynamic) is a vehicle that is supported above the surface (water, ice, soil, overpass, etc.) by the forces of excess air pressure constantly pumped under the bottom into a cavity called an air cushion. The static cushion is created by fans pumping air under the body of the vehicle, and the dynamic cushion is created by forcing the air flow under the body and wings of the transport module in a natural way during movement, it is based on the"screen effect".

The first working prototypes of such transport appeared in France in the 70s of the last century. The project, called "Aerotrain", was implemented by engineer J. Bertin. Aerotrain set a speed record of $430 \mathrm{~km} / \mathrm{h}$ on the eighteen - kilometer test track built between Saran and Rouen. Unlike magnetolevitation analogues, such transport was not burdened with expensive and complex technical equipment, and the most significant item of expenditure in the construction of lines concerned the construction of reinforced concrete overpasses. In the UK, in the same years, work was carried out on a similar technology "Hovertrain". The probability of building a developed network of such trains throughout Europe was quite high, however, after the death of $\mathrm{Zh}$. Bertin, the trend of development of the transport system has changed in the direction of the creation of high-speed railways TGV.

In our country, a serious school of scientific study and practical implementation of the use of airbags in transport systems has been created, starting with K. E. Tsiolkovsky. For example, under the guidance of designer R. E. Alekseev, a whole series of famous ekranoplans was created. One of them is the ekranoplan KM-7, called the "Caspian Monster", which, with a mass of 540 tons and a length of $100 \mathrm{~m}$, developed a speed of over $500 \mathrm{~km} / \mathrm{h}$. However, at present, hovercraft (SVP) are operated so far only mainly for emergency and military transport. One of the largest in the world is a ship hovercraft "Bison".

One of the most promising projects of high-speed transport today, in our opinion, is the aero-overpass transport (AEST), based on the combination of a dynamic air cushion with a special design of the mobile module and the aeroestack (screen). Active research of this concept is conducted by scientists from Novosibirsk V. G. Sokolov, A. N. Serieznov and T. A. Vladimirova. 
The coefficient of aerodynamic quality of AEST significantly exceeds the performance of well-known airliners, and in terms of energy efficiency, the project has a number of advantages over maglev trains: the payload is much higher. Also AECT features: low material consumption for construction of the route (on average, three times less than in the construction of rail lines), and, consequently, the cost of its construction; slight alienation of land to accommodate the foundations of the pillars (up to $0.1 \mathrm{ha} / \mathrm{km}$ ); low specific energy consumption (at a speed of $600 \mathrm{~km} / \mathrm{h}$. - $0.15 \mathrm{hp} / \mathrm{kgf}$.); environmental friendliness (low noise, no harmful emissions into the atmosphere); no vibration impact on the soil; allweather and all-season; the track is easily implemented in urban infrastructure. The creation and application of AEST will entail the introduction of a number of innovations and will have a real multiplicative effect.

AEST can also be built in permafrost areas, where classical transport communications are too expensive. This transport opens up wide opportunities for the development of remote and harsh territories of the east of Russia. On the basis of the AEST, it is possible to create unique tourist routes, such transport can be used for the country's defense complex.

\section{Problems of implementation of a new generation transport system and prospects for their application in Russia}

The construction of above-ground transport will require substantial investment and creation of mechanisms of organizational and legal structures of specific projects.

The feasibility of introducing AEST into the transport system is not in doubt, but there are problems in assessing the effectiveness of such implementation (traditional assessment methods are not suitable here) and the presence of barriers to the entry of new technology into the "field" occupied by large "players" in the same field of activity. In the absence of state support, sponsors and powerful market institutions, any new theoretically effective technology can become unrealized and go to another country where such conditions are created [14]. Unfortunately, in Russia, support for innovative projects is difficult. The crisis of the national innovation system is manifested in insufficient state financing of innovations. One of the reasons for this is the weak justification of the system of goals and priorities in the state innovation policy - for example, fundamentally important innovations related to the adoption and implementation of decisions in strategically important sectors of life support, which, first of all, includes transport, are not considered a priority.

The Government is wary of innovative high-speed modes of transport and still prefers the conservative "wheel-rail" technology. At the same time, if earlier the reason for this was the inability to fully integrate such technologies into the existing transport network, the lack of an appropriate scientific and technical base and the possibility of providing production volumes with conservative modes of transport, now these reasons are sharply losing relevance.

When implementing this project, there may be financial constraints and risks associated with high costs for licensing, testing, and technological training; changes in the exchange rate of the Russian currency; reduction of budget funds allocated to finance projects within the framework of state programs and other targeted activities. In order to reduce the negative consequences of such risks, it is necessary, first of all, to share risks and costs, to focus on the creation of partnerships within project consortia; the use of special credit financing; attracting the financial resource potential of municipalities, regions, large transport companies and companies that are interested in creating and developing this transport industry and related industries. 


\section{Conclusions}

It can be expected that investments in high-speed aboveground transport will be more effective in comparison with investments in exhausted transport technologies that have far exceeded the century-old milestone. Russia has the greatest economic potential from the construction of such transport on its territory - this is the acceleration of production processes, GDP growth by tens of trillions of rubles, the creation of new highly qualified jobs and other positive socio-economic effects. Such technologies open up real prospects for the transport development of the north-east of the country. Without the introduction of innovations in the transport sector, we will lose our territories with the richest resources.

\section{References}

1. O. Kherbash, M. Liviu Mocan, Procedia Economics and Finance 27, $42-47$ (2015)

2. J.G.S.N. Visser, Tunnelling and Underground Space Technology 80, 123-127 (2018)

3. C. Farias Almeida, J. Gomes Gularte, Y. Yamashita, Procedia - Social and Behavioral Sciences 162, 90-100 (2014)

4. P.P. Kumar, M. Parida, M. Swami, Procedia - Social and Behavioral Sciences 104, 795-804 (2013)

5. A. Idri, M. Oukarfi, A. Boulmakoul, K. Zeitouni, A. Masri, Procedia Computer Science 109, 692-697 (2017)

6. L. Zhang, H. Yang, D. Wu, D. Wang, Transportation Research Part C: Emerging Technologies 49, 73-86 (2014)

7. Wenyi Xia, Anming Zhang, Journal of Air Transport Management 65, 181-190 (2017)

8. F. Calvo-Poyo, S. Freiria, A. Medialdea, A. Antunes, Transportation Research Procedia 33, 251-258 (2018)

9. R. Schodl, S. Eitler, B. Ennser, A. Breinbauer, B. Hu, K. Markvica, M. Prandtstetter, J. Zajicek, T. Berger, S. Pfoser, C. Berkowitsch, G. Hauger, Transportation Research Procedia 30, 342-349 (2018)

10. Jian Chai, Youhong Zhou, Xiaoyang Zhou, Shouyang Wang, Zhe George Zhang, Zenghui Liu, Transportation Research Part A: Policy and Practice 108, 35-44 (2018)

11. T. Sato, M. Shiraishi, Transportation Research Procedia 48, 150-167 (2020)

12. N.A. Alexander, M.M. Kashani, Structures 14, 69-74 (2018)

13. A. Rutkin, New Scientist 230(3074), 20-21 (2016)

14. W. Schade, Transportation Research Procedia 14, 4105-4112 (2016) 